\title{
Investigation of the strength loss of glass fibre after thermal conditioning
}

\author{
P.G. Jenkins ${ }^{\mathrm{a}}{ }^{*}$, L. Yang ${ }^{\mathrm{a}}$, J.J. Liggat ${ }^{\mathrm{b}}$ and J.L. Thomason ${ }^{\mathrm{a}}$ \\ ${ }^{a}$ University of Strathclyde, Department of Mechanical \& Aerospace Engineering, 75 \\ Montrose Street, Glasgow G1 1XJ, United Kingdom. \\ ${ }^{\mathrm{b}}$ University of Strathclyde, Department of Pure and Applied Chemistry, 295 Cathedral \\ Street, Glasgow G1 1XL, United Kingdom \\ *peter.jenkins@strath.ac.uk (+44 7861 757559); 1.yang@strath.ac.uk; \\ j.j.liggat@strath.ac.uk; james.thomason@strath.ac.uk
}

\begin{abstract}
Single fibre tensile testing of thermally conditioned water sized and $\gamma-$ aminopropyltriethoxysilane (APS) sized boron-free E-glass has been carried out. The fibres were produced from identical melts following which bare fibre had only water applied to it before winding whereas the sized fibre had a solution containing only APS applied to its surface. Both fibre types experience a loss of room temperature tensile strength after exposure to elevated temperature. By application of a novel method of single fibre thermal conditioning it was demonstrated that the tensile strength of heat treated glass fibre can be significantly underestimated. Strength loss was found, in most cases, to be caused by a combination of thermal effect and mechanical handling damage. The latter is found to be influenced by thermal loading of the fibre. The onset of mechanical handling damage in APS sized fibre was found to be controlled by the thermal degradation of the silane sizing. This suggests that silane-based coatings, even when they are present as only a relatively thin surface layer, can protect fibres from the development or growth of critical surface flaws. The relative contribution to overall fibre strength loss from mechanical handling damage highlights the need to minimise processes which may cause fibre mechanical damage during glass fibre recycling procedures.
\end{abstract}

Keywords: Glass fibres, Strength, Thermomechanical properties, Thermogravimetric analysis

\section{Introduction}

Glass fibre has been the predominate reinforcement for polymer composites over the past decades owing to its high specific properties and low cost. Consequently a large volume of glass fibre reinforced composites has been employed widely in many industries. The continuing growth of their use is driven now by sectors such as transportation, renewable energy, and construction [1]. Such massive use of the material has led to issues surrounding disposal of glass fibre reinforced composites at the end of their product lifetimes. For example, glass fibre-thermoset composites can be particularly problematic to deal with in terms of recycling and reuse.

Numerous technologies exist for the reuse of thermoset composites, such as mechanical grinding or combusting for energy and material recovery (for example in cement kilns). It has been commented upon that the fibre fraction in recycled composites may be the most valuable if it were recoverable [2]. Separating fibre from matrix is always challenging and requires the application of heat. Yet it has previously been reported that heating tends to cause a significant degree of strength loss in glass fibre [3, 4]. In this context, it is important to understand at a fundamental level the mechanisms by which 
the strength of glass fibre is reduced during composite recycling processes, in which exposure to elevated temperature is ubiquitous. Early investigations $[5,6]$ on uncoated pristine E-glass showed that higher treatment temperatures cause greater strength loss and that given a long enough processing time at a given temperature the retained fibre strength will approach an asymptotic minimum. Similar results for other glass compositions have also been reported $[7,8]$.

The failure of a brittle material such as glass fibre in tension is generally accepted to be controlled by the presence of flaws [9] with the most critical surface flaw thereby being the point at which failure will occur at a corresponding critical applied stress. It follows that any process which causes new surface flaws, or grows existing flaws, will facilitate a drop in fibre tensile strength - for example a fluidised bed process such as the one reported in [3]. On a similar theoretical basis, it has been often postulated that applying surface coatings to glass fibres leads to increased tensile strengths because of a flawhealing mechanism $[10,11]$. Conversely, removing the surface coating from a sized glass fibre should lead to a decrease in strength. Feih et al. [4] showed this to be the case using fully sized E-glass fibre, upon which the sizing system is often a combination of the silane coupling agent, film former, lubricant and potentially other functional molecules. Exposure to high temperatures caused significant strength loss and this was correlated with the degradation of the sizing as evidenced by TGA measurement. Such data, using fully sized fibres, exists in the literature. Less prevalent, however, are recent data for bare fibre. It seems logical that the most useful data could be produced by comparative studies using both sized and bare fibre produced by the same manufacturer. This would eliminate any differences in glass composition or thermal history of the fibres.

In some of the earliest research (during the 1960s) on the effects of temperature on glass fibre strength, fibres were heat treated individually with great care and control [5]. This is logical as it is accepted that damage to the surface even during handling may initiate surface cracks, however this work required the availability of the glass fibre bushing to researchers. Conversely, in other work $[12,13]$ glass fibre has been thermally treated in bundles (as provided) with single fibre samples then being removed for tensile testing. In the work presented here this potential source of fibre damage - removal from the heat treated bundle - was investigated by applying a novel single fibre thermal conditioning technique. Fibre tensile strengths were obtained by single fibre tensile testing.

Investigation of fibre surfaces by SEM, and thermal analysis of the aminosilane coating, was also carried out. This was applied to both bare and silane-coated fibre to investigate the protective effects attributed to such surface coatings and how they respond during exposure to elevated temperatures.

\section{Experimental}

\subsection{Materials}

Boron-free E-glass (Advantex) fibres supplied by Owens Corning Vetrotex were investigated in this study. All fibre rovings were produced on the same pilot scale bushing and were received as $20 \mathrm{~kg}$ continuous single-end square edge packages. The rovings had a nominal tex of $1200 \mathrm{~g} / \mathrm{km}$ and a single-fibre diameter of $17.4 \pm 1.3 \mu \mathrm{m}$. No sizing was applied to the bare fibres which had only been water sprayed using the normal cooling sprays under the bushing; these samples are referred to as water sized or bare (since it can be assumed that most water is removed during the subsequent drying 
step). Immediately following an identical cooling step by water spraying, the sized fibres were coated with a normal rotating cylinder sizing applicator containing a $1 \% \gamma-$ aminopropyltriethoxysilane (APS) hydrolysed solution in distilled water. This silane coating process produced fibres with significantly lower weight percentage coating compared to commercially available glass fibre products. All fibre packages were subsequently dried at $105^{\circ} \mathrm{C}$ for 24 hours. Pure APS, supplied by Sigma Aldrich, was used to make an APS film. A 1 vol\% APS solution was produced in a polypropylene container with deionised water and oven-dried at a constant $105^{\circ} \mathrm{C}$. Once formed the film was stored in a desiccator containing silica gel.

\subsection{Thermal Conditioning}

A great deal of thermal conditioning (or heat treatment, the two are synonymous in this paper) of glass fibre was carried out in the research work presented. All heat treatments were carried out in a radiative furnace for 25 minutes. Ten minutes of re-heating were allowed to reach the target temperature and thereafter a 15 minute thermal conditioning period took place. This treatment time approximately reflects the length of some similar thermal recycling treatments found in the literature [3, 14]. After treatment, all samples were cooled immediately in room temperature air.

Two different thermal conditioning protocols were developed and used in the work: bundle thermal conditioning and single fibre thermal conditioning. In the former, lengths of the fibre roving were treated at the desired temperature and, after cooling, single fibres removed for testing. Conversely, in the single fibre thermal conditioning process single fibres were extracted from a bundle prior to thermal conditioning. These were then attached to individual wire frames using cement and thermally conditioned in batches of around 30 fibres. In both processes fibres, or fibre bundles, were supported at both ends so that no longitudinal tensile stresses were applied. Fibres were mounted with some slack along the length rather than being held tightly between the two fixing points. This ensured that thermal expansion of the frame would not induce longitudinal tensile stress. Secondly, it was possible for fibres to flex due to convective air currents; bending stresses caused by this were thus most concentrated at the fibre ends which did not form part of the tested gauge length. Therefore, the only difference between the two processes was the point of fibre separation from the bundle as indicated in Fig. 1.

\subsection{Single Fibre Tensile Test}

Tensile testing on as-received and heat treated fibre was carried out. Single fibre tensile properties were obtained according to the method described in ASTM C1557-03. The details of the procedure utilized are described comprehensively by Yang and Thomason in [15]. All fibres were mounted at a gauge length of $20 \mathrm{~mm}$. After each individual fibre diameter was measured by optical microscopy the samples were tested using an Instron 3342 universal testing machine equipped with a $10 \mathrm{~N}$ load cell. An extension rate of 0.3 $\mathrm{mm} / \mathrm{min}$ was used in all cases. The average strength values at each condition are based on between 20 and 80 tensile tests. Due to the large number of tensile tests carried out the effect of potential errors in the measurement of fibre diameter on average tensile strength was modest. All tests were carried out at room temperature and approximately $50 \%$ relative humidity.

\subsection{SEM Imaging}

Numerous high resolution images of the surfaces of glass fibres were captured using a Hitachi SU6600 Field Emission SEM (FE-SEM). Images were taken at an accelerating 
voltage of $15 \mathrm{kV}$ and extraction voltage $1.8 \mathrm{kV}$. Both as received and fibres conditioned by the single fibre thermal conditioning method were imaged. In all cases the samples were gold coated prior to making observations.

\subsection{Thermal analysis}

Thermal analyses were carried out using a Netzsch STA 449 F1 Jupiter. Dedicated TGA was conducted in an alumina beaker while simultaneous TGA/DSC measurements were made using platinum pans. Approximately $100 \mathrm{mg}$ of sample was analysed during TGA and $10 \mathrm{mg}$ during TGA/DSC. The thermal profile applied in all cases was a ramp of 10 ${ }^{\circ} \mathrm{C} / \mathrm{min}$ from room temperature to $1000^{\circ} \mathrm{C}$, following which the sample was allowed to cool to room temperature.

A Hiden CATLAB ${ }^{\mathrm{TM}}$ was used to conduct thermo-chemical analysis. The CATLAB consists of a microreactor with temperature and gas flow control, coupled to a Hiden QIC-20 mass spectrometer, allowing temperature resolved identification of volatile species over the range 2-200 AMU. Samples of the order of $1 \mathrm{mg}$ were placed into a borosilicate glass tube which was then inserted into the furnace. A ramp rate of 10 ${ }^{\circ} \mathrm{C} / \mathrm{min}$ from room temperature to $550{ }^{\circ} \mathrm{C}$ was chosen, to reflect the TGA/DSC previously described. The purge gas was helium at a flow rate of $40 \mathrm{ml} / \mathrm{min}$.

\section{Results and Discussion}

\subsection{Bundle Thermal Conditioning}

Bare and APS sized fibres were thermally conditioned using the two methods described, at several temperatures between 200 and $600{ }^{\circ} \mathrm{C}$. The average single fibre tensile strengths (error bars show $95 \%$ confidence limits in all figures) measured at room temperature following bundle heat treatments are presented in Fig. 2.

The APS sized fibre initially has much higher room temperature strength than bare, which is not surprising as it is protected from surface damage by the silane coating. For sized fibre, around $20 \%$ of this strength had been lost after a treatment temperature of $300{ }^{\circ} \mathrm{C}$. The strength loss increased greatly above $300^{\circ} \mathrm{C}$ and became much less dependent on conditioning temperature beyond $500^{\circ} \mathrm{C}$. The bare fibre, on the other hand, lost over half its original strength by $300^{\circ} \mathrm{C}$ and in fact much of this loss was also observed when treating to just $200{ }^{\circ} \mathrm{C}$. At higher temperatures the bare fibre strength decreased further, but to a lesser degree that was just beyond the $95 \%$ confidence limits. Conversely, the strength of the sized fibre decreased most significantly at higher temperatures. Following treatment at $450{ }^{\circ} \mathrm{C}$ it retained only one third its original strength and after $500{ }^{\circ} \mathrm{C}$ treatment just one quarter: approximately the same absolute magnitude as measured for the bare fibre.

The strength of sized and bare fibre tended to converge as the thermal conditioning temperature increased. As the only difference between these two specimens is the presence of APS coating, it may be reasonable to state that strength retention resulting from the surface coating is compromised by thermal conditioning and can be completely dismissed after the temperature reaches $500{ }^{\circ} \mathrm{C}$. However, it is interesting to observe that bare fibre was subject to significant strength loss due to the thermal treatment applied in this work. It implies that some level of strength loss during heating could also be attributed to factors other than surface coating alone. It is widely accepted that loss of the protective sizing (for example at elevated temperature) is likely to contribute to strength loss but equally it is known that some other fundamental changes, 
independent of the sizing, occur in glass fibres at high temperatures [16-19]. The use of both bare and sized fibre in this work helps to separate the variable of sizing effect from other strength loss mechanisms in the glass.

Comparison of these data with those published in the literature is somewhat problematic. Although other researchers have shown strength loss data for thermally conditioned glass fibre, these are often only reported for sized fibre or fibre that has been recycled from a composite material. When data for bare fibre are published they are very often based on self-produced fibre, manufactured using single test bushings. In such cases thermal conditioning is therefore carried out on single fibres rather than bundles [5, 6, 17]. The sized fibre data presented in Fig. 2 may, however, be compared with those of Feih et al. [4, 13]. They present normalised fibre strengths following thermal conditioning at similar temperatures and times to those used in this work. In all cases they report slightly higher normalised retained strengths than reported here: for example at $450{ }^{\circ} \mathrm{C}$, a reduction of $50-55 \%$ compared to our $65 \%$, or $10-15 \%$ at 350 ${ }^{\circ} \mathrm{C}$ where we report a loss of around $20 \%$ at $300{ }^{\circ} \mathrm{C}$. These differences are most likely attributable to the fact that the fibres used in our work had a lower weight percentage of coating applied to them, although differing glass compositions or thermal histories may also have had an effect.

\subsection{Single Fibre Thermal Conditioning}

It was noted heuristically that the separation of single fibres from the bundle for tensile testing becomes progressively more challenging following thermal conditioning at higher temperatures. Consequently fibres broke more frequently during manual removal from the bundle despite the best efforts not to stress them in tension or bending. These observations led to the supposition that when a fibre is removed from a bundle that has been heat treated, even though it may not break, it may be subjected to some damage. This would weaken the fibre leading to an erroneous result, underestimating its true strength. To eliminate this potential source of error the single fibre thermal conditioning procedure outlined in Fig. 1 was developed. In Fig. 3 the bundle thermal conditioning data from Fig. 2 are presented in parallel with average tensile strengths of fibre treated using the single fibre thermal conditioning procedure.

Retained fibre strength decreased with an increase in thermal conditioning temperature and the difference in fibre strength was reduced as the thermal conditioning temperature increased. These two sets of data also converged between $500{ }^{\circ} \mathrm{C}$ and $600{ }^{\circ} \mathrm{C}$.

Furthermore, it is noticeable that the strength decay of the bare and the sized fibre after single fibre thermal conditioning shares a similar pattern over the temperature range investigated. This implies that there is a mechanism functioning in both fibre types which is responsible for strength loss. The magnitude of this strength loss may be characterised by the data obtained from singly conditioned bare fibres (the series Bare_single fibre) in Fig. 3. Both bare and sized fibre retained a significantly greater strength when thermal conditioning was carried out on single fibres rather than bundles. For bare fibre, this difference is evidenced at temperature as low as $200{ }^{\circ} \mathrm{C}$, whereas for the sized fibres it occurs after heat treating above $300{ }^{\circ} \mathrm{C}$.

The authors postulate that the cause for the divergence of the tensile strengths lies in the mechanisms of damage which affect the fibres, depending on the method by which they are thermally conditioned. In the single fibre thermal conditioning process, single fibres are removed from the bundle that is in the originally manufactured state. Any protective 
surface coatings that were added are still fully intact. During the thermal conditioning and tensile testing procedures some strength loss is observed: the higher the thermal conditioning temperature the greater the loss. Since the handling of the fibre is minimal, it seems reasonable to assume that the strength loss measured is predominately caused by exposure to elevated temperature: this is referred to as thermal damage. This type of damage may involve structural change in the surface and bulk of glass fibre. Ya et al. [20] recently experimentally characterised anisotropy relaxation and enthalpy relaxation for calcium boroalumosilicate E-glass fibre thermally treated below Tg. Their results showed that the release of excess enthalpy to be a time and temperature dependent process. Work on similar fibres by Lund and Yue [17] identified these structural changes as a possible explanation for reduction in residual fibre strength following annealing. Although the glass transition $\left(\mathrm{Tg}=760^{\circ} \mathrm{C}\right)$ has been reported for the fibres used in our study [16], structural relaxation still needs to be characterised for these fibres in order to further explain the single fibre thermal conditioning results in Fig. 3. However, our results presented in [16] showed a thermal compaction phenomenon, visible upon isothermal treatment to $300{ }^{\circ} \mathrm{C}$ but most significant in the region 400-500 ${ }^{\circ} \mathrm{C}$. This suggests some long-range structural rearrangement occurs within the fibre at these temperatures. The connection between this phenomenon and strength loss of glass fibre requires further investigation.

An alternative avenue of investigation regards the effects of thermal treatment on the surface hydroxyl state. Results produced using high surface area silica have indicated that the removal of hydroxyl groups occurs above $165^{\circ} \mathrm{C}$, and above $400{ }^{\circ} \mathrm{C}$ this dehydroxylation process becomes only partly reversible by exposure to water vapour [21]. A similar change in surface hydroxyl state of heat treated glass fibre may more immediately be imagined to affect surface bonding, but the possibility of it affecting the retained tensile strength has not been investigated. In contrast to single fibre thermal conditioning, in the bundle thermal conditioning process fibres were removed from a bundle that had been exposed to a given elevated temperature. The effect of this change compared to the single fibre thermal conditioning process is clear: at all treatment temperatures, bare fibres were significantly weakened, and beyond a temperature of 300 ${ }^{\circ} \mathrm{C}$ the same was true for sized fibres. This secondary source of tensile strength loss is described by the authors as mechanical handling damage. The onset of this phenomenon did not occur in the sized fibre until a treatment temperature of $300{ }^{\circ} \mathrm{C}$ was exceeded. The explanation for this is most likely connected with degradation of the APS coating.

Finally, it should be noted that length of exposure time to elevated temperature was not investigated as part of this work. It has been demonstrated in the literature $[4,5]$ that there exists a finite time taken for a given fibre at a given temperature to reach a steadystate minimum strength, and that this time decreases with increasing temperature.

Despite differences in material and thermal treatment applied, both the studies referenced produced similar conclusions. Using a treatment temperature of $450{ }^{\circ} \mathrm{C}$ around a 30 minute treatment was required to reach the steady state strength. For lower temperatures in the range $300-350{ }^{\circ} \mathrm{C}$ this time increased to approx. 1.5 to 2 hours. The authors conducted one preliminary set of tensile tests using APS fibre treated at 450 ${ }^{\circ} \mathrm{C}$ for 2.5 hours, approx. 5 times longer than the standard heat treatment in this work. The retained strength in this case was approx. 50\% of untreated value compared to $65 \%$ for the 25 minute treatment ( $1.17 \& 1.56 \mathrm{GPa}$ respectively). This evidences the limit of protective effect that the silane coating can provide; after a suitably long conditioning time the fibre strength is identical to that of bare fibre which has been heat treated for 25 
minutes. In the context of the heat treatment work we report on, the selection of a constant treatment time was appropriate nonetheless. It made it possible to identify any specific region(s) of strength loss which could then be further investigated by other means to attempt to discover what physical changes were responsible.

\subsection{Surface Imaging of Heat Treated Fibre}

While other investigations [4] have been able to utilise TGA to directly investigate fibre coating degradation this was not possible in this work, as the APS coating only constituted less than $0.05 \mathrm{wt} \%$ of the sample. Direct observation of the fibres was therefore made using SEM, while thermal analysis was performed using an APS film. Fig. 4 (a) shows a typical $450{ }^{\circ} \mathrm{C}$ treated APS sized fibre. The surface is largely featureless, and this type of observation was representative of fibres treated at all temperatures, except $300{ }^{\circ} \mathrm{C}$. As shown in Fig. 4 (b), some areas of the surface of fibres treated at this temperature exhibited what appear to be convex, dome-like, structures dispersed randomly across the fibres. Interpreting results from SEM pictures alone can be challenging, and many differing explanations for the same phenomenon might be offered, but in this case the authors suggest one plausible explanation. The convex structures are created by the volatilization of the APS surface coating - much the same as might be observed on a painted surface that is subject to high temperatures. A temperature of $300{ }^{\circ} \mathrm{C}$ would appear to be critical for the sized fibre under investigation; this is approximately the temperature at which part of the silane coating may be volatilised, such that it can no longer provide sufficient protection to the fibre surface. This temperature also coincides with the onset temperature of faster and more significantly strength loss in sized fibre as seen in Fig. 3.

\subsection{Thermal Degradation of APS}

In order to provide further evidence to help interpret the results in Fig. 2 and 3, a study of APS degradation was performed using several thermal analysis techniques described earlier and the results obtained from these techniques were combined to generate more insight into APS thermal degradation. Results of simultaneous TGA/DSC, confirmed by repeat analyses, are presented in Fig. 5. The shape of the mass loss curve alone was also confirmed by performing dedicated TGA using a larger sample mass in an alumina beaker.

An initial endothermic process was found in the range $20-225^{\circ} \mathrm{C}$, during which a mass loss of almost $10 \%$ occurred. Comparison with data from the CATLAB analysis (Fig 6 (a) and (b)) shows this transition to be due to the evolution of water. This water comes in small part from water trapped during the preparation of the film from aqueous solution and in large measure from the condensation reaction that occurs during the curing of the APS film as it forms a cross-linked polymer network [22]. CATLAB analysis, Fig. 6 (c), shows also considerable evolution of $\mathrm{CO}_{2}$ from the film below 200 ${ }^{\circ} \mathrm{C}$. The source of this $\mathrm{CO}_{2}$ is not believed to be from the degradation of any part of the APS film but rather is due to the release of bound atmospheric $\mathrm{CO}_{2}$. It has been shown by Culler et al. [23] that triamine coated E-glass mats dried under air will produce trapped $\mathrm{CO}_{2}$ gas when subsequently heated above $100{ }^{\circ} \mathrm{C}$.

The volatilisation reaction of the APS film becomes rapidly exothermic beyond approximately $225^{\circ} \mathrm{C}$ and the lowest of three peaks occurs at $245^{\circ} \mathrm{C}$. The region of maximum mass loss of the film commences at around $300{ }^{\circ} \mathrm{C}$ with the maximum rate of mass loss occurring at around $440{ }^{\circ} \mathrm{C}$. This corresponds to the degradation of the 
organic fraction of the polymer chain, and by comparing Fig. 6 (b) and (d) it appears that the mass loss from approx. $300-350{ }^{\circ} \mathrm{C}$ is due to volatilisation of $\mathrm{NH}_{3}$. Fig. 6 (d) shows that a peak in the volatilisation of $\mathrm{C}_{2} \mathrm{H}_{4}$ occurred at around $400{ }^{\circ} \mathrm{C}$. This is a product of the direct fragmentation of the propyl chains of the cross-linked APS polymer, which occurs once the temperature has exceeded $350^{\circ} \mathrm{C}$. A separate CATLAB analysis performed under dry air showed, instead of $\mathrm{C}_{2} \mathrm{H}_{4}$ due to fragmentation, a strong $\mathrm{CO}_{2}$ signal in this temperature range due to complete combustion of the organic fraction.

These results further confirm the hypothesis that degradation of the single-component sizing system (APS only) can explain the divergence of the strength values for sized fibre in Fig. 3. At temperatures around $300{ }^{\circ} \mathrm{C}$ and below, very little mass loss (not associated with water or $\mathrm{CO}_{2}$ ) had occurred. This suggests that the polymeric structure of the film had not degraded significantly at this stage; hence the APS sized fibre surface should be still largely protected by the coating up to $300{ }^{\circ} \mathrm{C}$. The weight percentage of APS on the surface of the fibre used in this work is orders of magnitude less than the pure APS film with which thermal analyses were carried out. However, one of the currently accepted models of the APS coated glass fibre surface suggests that the APS exists as a disordered, cross-linked polymeric network which is largely bonded to its own molecules, with only a thin layer also bonded to a glass surface [24]. The structures of APS film and coated fibre are therefore relatively similar, so that experimental results obtained for one may be applicable to the other. In this case it seems reasonable that a temperature in excess of $300{ }^{\circ} \mathrm{C}$ was required to significantly degrade the APS surface coating of fibre, just as it was for the film. The initial stages of this process may be what can be observed in the SEM images (Fig. 4) of fibre treated at $300{ }^{\circ} \mathrm{C}$. During bundle thermal conditioning below $300^{\circ} \mathrm{C}$, extracting fibres from the treated bundle did not induce any further mechanical handling damage as sufficient coating remained as protection on the fibres. Conversely, when thermal conditioning was performed beyond $300^{\circ} \mathrm{C}$ far more APS coating was removed by thermal volatilisation. Bundle conditioned sized fibres suffered further mechanical handling damage (on top of the thermal damage) during removal from the bundle. Hence the bundle thermal conditioning strengths were significantly lower. Interestingly, at both $500{ }^{\circ} \mathrm{C}$ and $600{ }^{\circ} \mathrm{C}$ it appeared to make little difference whether or not the fibres had been coated in the first place: for bundle thermal conditioning the strength of both fibre types was approx. $0.55 \mathrm{GPa}$. Based on the results presented in this work, one can see that there may be at least two mechanisms responsible for the strength loss in heattreated glass fibre. The first may be associated with structural relaxation of the fibre surface and/or bulk volume, or with dehydroxylation of the fibre surface, as well as diffusion of bulk water. The second is related to mechanical handling. The effect of both mechanisms on strength loss is strongly influenced by the conditioning temperature through thermodynamics of the hyperquenched glass structure and thermal stability of surface coating respectively.

It must also be recognised that the weight loss of around $2 \%$, which corresponds with the first exothermic peak in Fig. 5, has not been fully explained at this stage, although it is a reproducible phenomenon. While the major weight loss $\left(300{ }^{\circ} \mathrm{C}\right.$ to $\left.700{ }^{\circ} \mathrm{C}\right)$ is due to degradation of organic chains within the APS molecule, the exothermic process which occurs at this lower temperature has not yet been established. Preliminary results obtained by TGA/DSC under inert atmosphere, however, suggest it is an oxidative reaction. Further research into this aspect of APS thermal degradation will be carried 
out since any changes in - or break down of - the APS molecule at such low temperature might have important implications for first pass composite processing as well as glass fibre recycling.

\section{Conclusions}

The dual effects of thermal and mechanical handling damage on the strength of thermally conditioned glass fibre have been demonstrated by application of both bundle, and the novel single fibre, thermal conditioning methods to both bare and APS coated E-glass fibre. Using single fibre thermal conditioning it was possible to achieve significantly greater retained strengths in cases where the glass fibre had no, or inadequate, surface protection, in the form of APS sizing. It was for this reason that a disparity in retained strengths for sized fibre was only observed when thermal conditioning was performed above $300{ }^{\circ} \mathrm{C}$, whereas the bare fibre system exhibited the effect even upon heating at relatively low temperatures. Convergence of the bundle thermal conditioning data (Fig. 2) suggests that the protective effect of the APS coating against mechanical handling damage is completely removed by a conditioning temperature of $500{ }^{\circ} \mathrm{C}$. This result emphasises the importance of minimising surface damage to glass fibres during recycling processes as any mechanical handling further reduces the fibre strength. Further, it demonstrates the ability of even very low weight percentage silane-based coatings to protect the surface of glass fibres from the further development of surface flaws contributing to a reduction in strength. Tensile strength results obtained using the single fibre thermal conditioning procedure allow us to observe a similar pattern of strength loss for both bare and APS sized fibre. Both fibre types may be subject to the same thermal damage mechanism. The nature of this thermal damage, and how it influences the tensile strength of heat treated glass fibre, is not yet fully understood. The relationship between this fundamental strength and changes in the glass, such as surface dehydroxylation and structural relaxation, requires further research.

It was confirmed that, similar to full glass fibre sizing systems, the critical degradation range for APS films initiates at around $300{ }^{\circ} \mathrm{C}$, based on TGA/DSC and CATLAB Mass Spectrometry measurements. Direct SEM observation of heat treated sized fibres also suggested that $300{ }^{\circ} \mathrm{C}$ was a critical degradation onset temperature for APS on a glass fibre surface. It was found in the range $350-550{ }^{\circ} \mathrm{C}$ the organic fraction of the polymeric chain structure of the APS molecules degrades significantly as evidenced by the presence of peaks in the mass spectrometry measurements of $\mathrm{C}_{2} \mathrm{H}_{4}$. This coating degradation was associated with the observed difference in retained strength of sized fibre heat treated beyond $300{ }^{\circ} \mathrm{C}$, dependent on whether the bundle or single fibre treatment method was used.

\section{Acknowledgement}

The authors gratefully acknowledge the funding from Engineering and Physical Sciences Research Council (EPSRC) through the project EP/I038616/1. The authors would also like to thank Owens Corning Vetrotex for providing the glass fibres used in this study. Special thanks are given to the Advanced Materials Research Laboratory (AMRL) at University of Strathclyde for the use of TGA, DSC and SEM equipment. 


\section{References}

1. (2014) Glass Fiber \& Glass Fiber Reinforced Plastic (GFRP) Composites Market by Raw Material, Manufacturing Process, Application \& by Geography - Global Trends \& Forecast to 2019. 1-347.

2. Pickering SJ (2006) Recycling technologies for thermoset composite materialscurrent status. Compos Part A Appl Sci Manuf 37:1206-1215. doi: 10.1016/j.compositesa.2005.05.030

3. Kennerley JR, Fenwick NJ, Pickering SJ, Rudd CD (1997) The properties of glass fibers recycled from the thermal processing of scrap thermoset composites. J Vinyl Addit Technol 3:58-63. doi: 10.1002/vnl.10166

4. Feih S, Boiocchi E, Mathys Z, et al. (2011) Mechanical properties of thermallytreated and recycled glass fibres. Compos Part B Eng 42:350-358. doi: 10.1016/j.compositesb.2010.12.020

5. Thomas WF (1960) An investigation of the factors likely to affect the strength and properties of glass fibres. Phys Chem Glas 1:4-18.

6. Cameron NM (1968) The effect of environment and temperature on the strength of Eglass fibres. Part 2. Heating and ageing. Glas Technol 9:212-130.

7. Aslanova MS (1960) The Effect of Different Factors on the Mechanical Properties of Glass Fibers. Steklo i Keramika 17:10-15.

8. Dorzhiev DB, Khazanov VE, Gorbachev V V (1990) Some features of the structure and strength of a magnesium aluminosilicate fiber. Sov J Glas Phys Chem 15:99102.

9. Griffith AA (1921) The Phenomena of Rupture and Flow in Solids. Philos Trans R Soc A Math Phys Eng Sci 221:163-198. doi: 10.1098/rsta.1921.0006

10. Zinck P, Mader E, Gerard JF (2001) Role of silane coupling agent and polymeric film former for tailoring glass fiber sizings from tensile strength measurements. J Mater Sci 36:5245-5252.

11. Gao S, Mader E, Plonka R (2008) Nanocomposite coatings for healing surface defects of glass fibers and improving interfacial adhesion. Compos Sci Technol 68:2892-2901. doi: 10.1016/j.compscitech.2007.10.009

12. Jenkins P, Thomason J, Meier R (2012) Separation of mechanical and thermal degradation of thermally conditioned sized glass fibre. ECCM15 - 15th Eur. Conf. Compos. Mater.

13. Feih S, Manatpon K, Mathys Z, et al. (2008) Strength degradation of glass fibers at high temperatures. J Mater Sci 44:392-400. doi: 10.1007/s 10853-008-3140-x 
14. Mizuguchi J, Tsukada Y, Takahashi H (2013) Recovery and Characterization of Reinforcing Fibers from Fiber Reinforced Plastics by Thermal Activation of Oxide Semiconductors. Mater Trans 54:384-391.

15. Yang L, Thomason JL (2012) Effect of silane coupling agent on mechanical performance of glass fibre. J Mater Sci 48:1947-1954. doi: 10.1007/s10853-0126960-7

16. Yang L, Thomason JL (2013) The thermal behaviour of glass fibre investigated by thermomechanical analysis. J Mater Sci. doi: 10.1007/s10853-013-7369-7

17. Lund MD, Yue Y (2010) Impact of Drawing Stress on the Tensile Strength of Oxide Glass Fibers. J Am Ceram Soc 93:3236-3243. doi: 10.1111/j.15512916.2010.03879.x

18. Aslanova MS, Ivanov N V, Balashov YS (1970) Effect of chemical composition on the relaxation properties of thin glass fibers. Steklo i Keramika 8:21-24.

19. Otto WH (1961) Compaction Effects in Glass Fibers. J Am Ceram Soc 44:68-72.

20. Ya M, Deubener J, Yue Y (2008) Enthalpy and Anisotropy Relaxation of Glass Fibers. J Am Ceram Soc 91:745-752. doi: 10.1111/j.1551-2916.2007.02100.x

21. Hair ML (1975) Hydroxyl groups on silica surface. J Non Cryst Solids 19:299-309.

22. Masmoudi M, Rahal C, Abdelmouleh M, Abdelhedi R (2013) Hydrolysis process of $\gamma$-APS and characterization of silane film formed on copper in different conditions. Appl Surf Sci 286:71-77. doi: 10.1016/j.apsusc.2013.09.018

23. Culler SR, Naviroj S, Ishida H, Koenig JL (1983) Analytical and Spectroscopic Investigation of the Interaction of $\mathrm{CO} 2$ with Amine Functional Silane Coupling Agents on Glass Fibers. J Colloid Interface Sci 96:69-79.

24. Liu XM, Thomason JL, Jones FR (2008) XPS and AFM Study of Interaction of Organosilane and Sizing with E-glass Fibre Surface. J Adhes 84:322-338. 


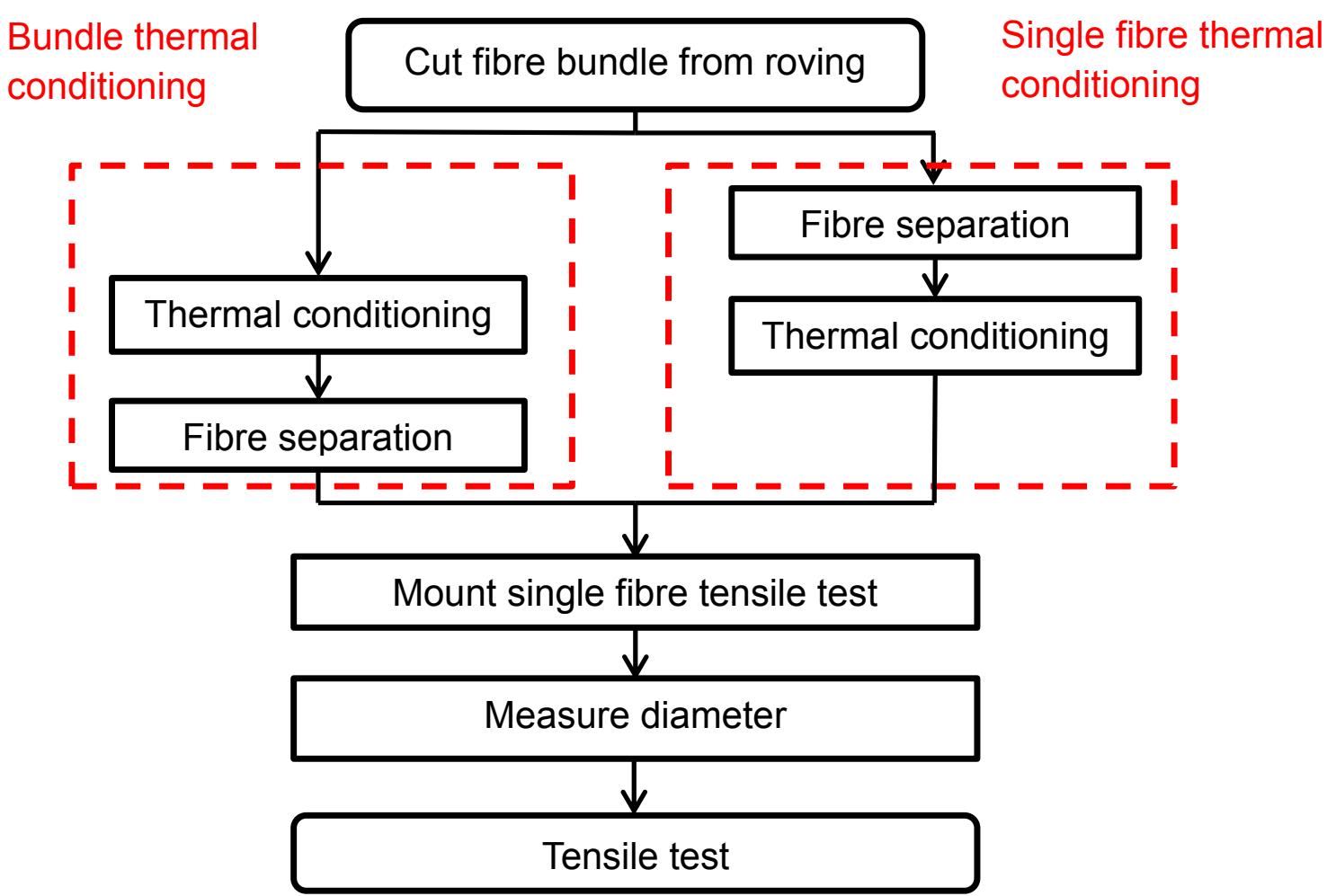

Fig. 1 Simplified flowchart showing the difference between the bundle and single fibre thermal conditioning procedures

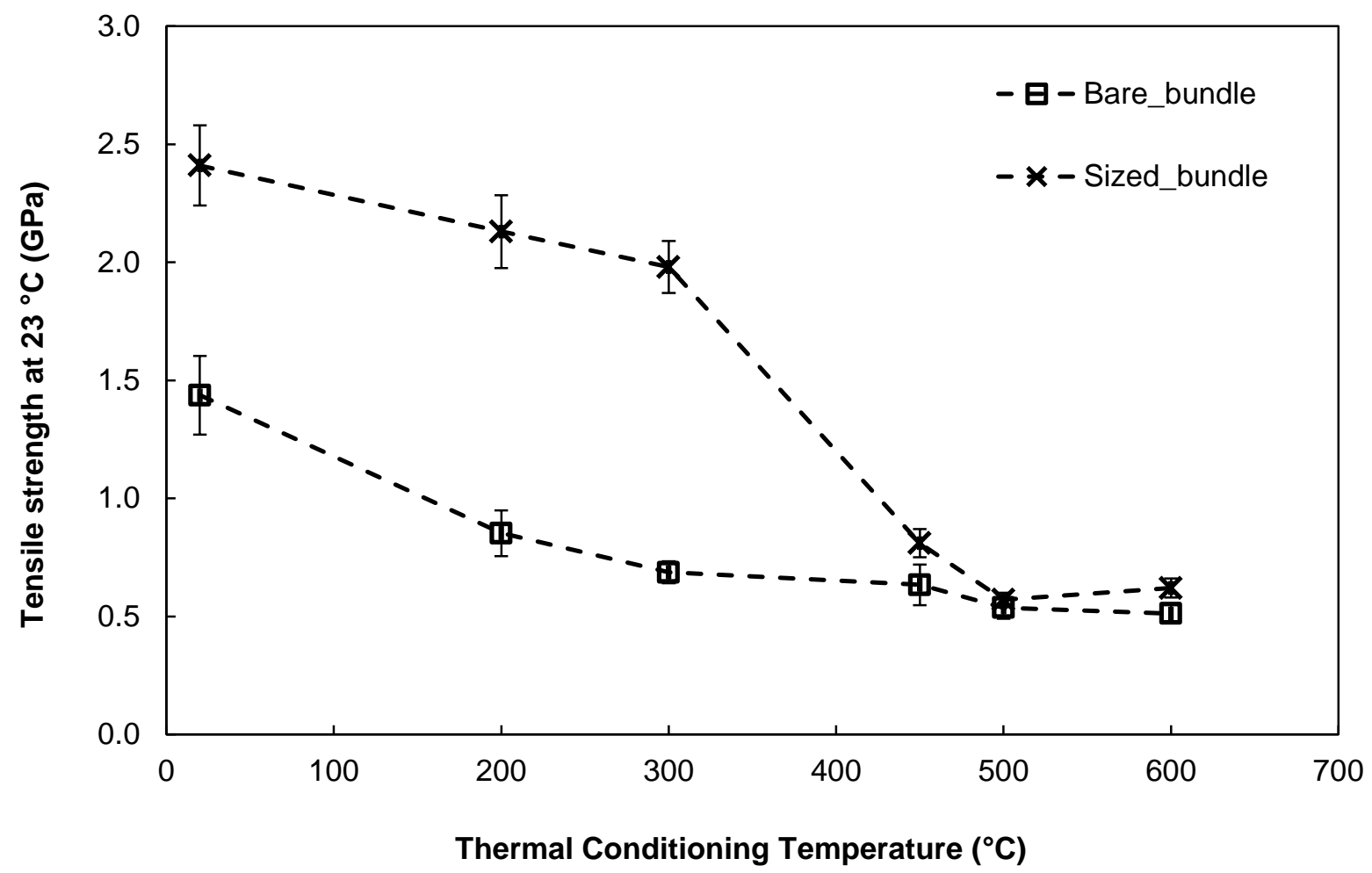

Fig. 2 Tensile strength of bare and APS sized fibres after bundle thermal conditioning at $200,300,450,500 \& 600{ }^{\circ} \mathrm{C}$ for 25 minutes 


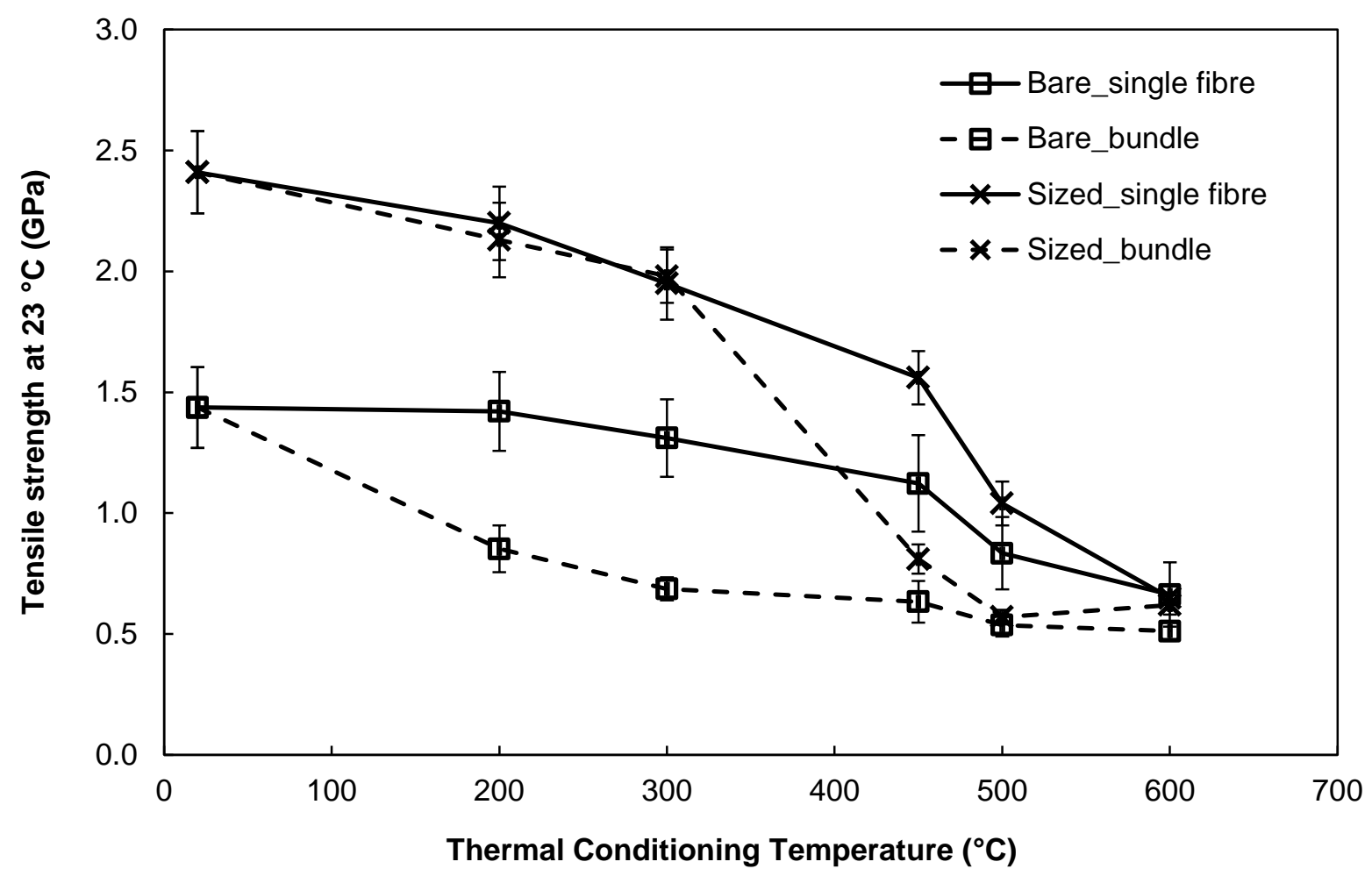

Fig. 3 Tensile strengths of bare and APS sized fibres after thermal conditioning at 200, $300,450,500 \& 600^{\circ} \mathrm{C}$ for 25 minutes 


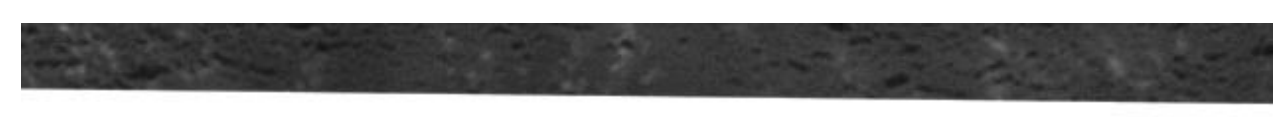

(a)
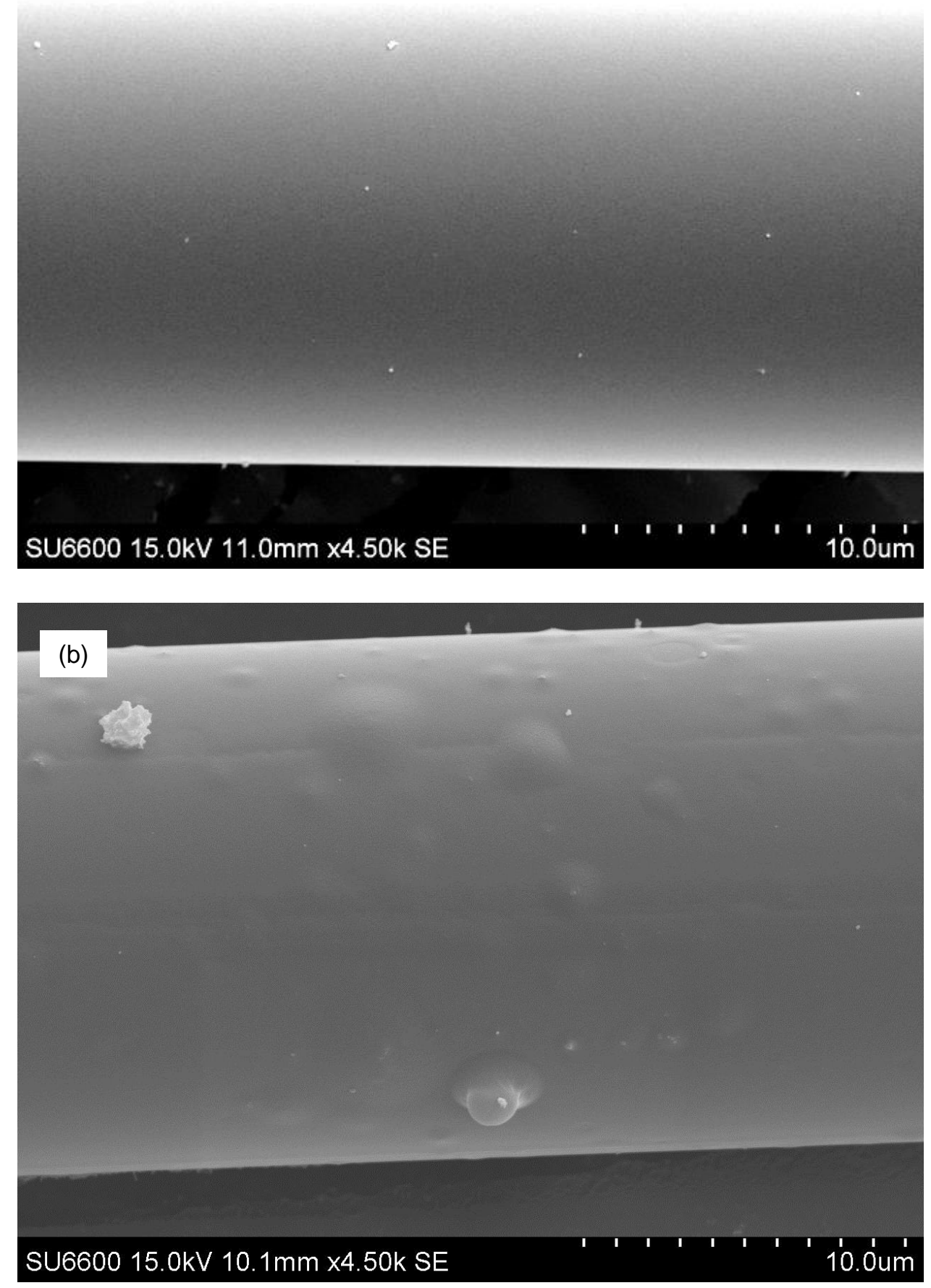

Fig. 4 SEM images of (a) $450{ }^{\circ} \mathrm{C}$ thermally conditioned, and (b) $300{ }^{\circ} \mathrm{C}$ thermally conditioned APS coated fibre surface. Single fibre conditioning procedure and treatment time of 25 minutes used in both cases 


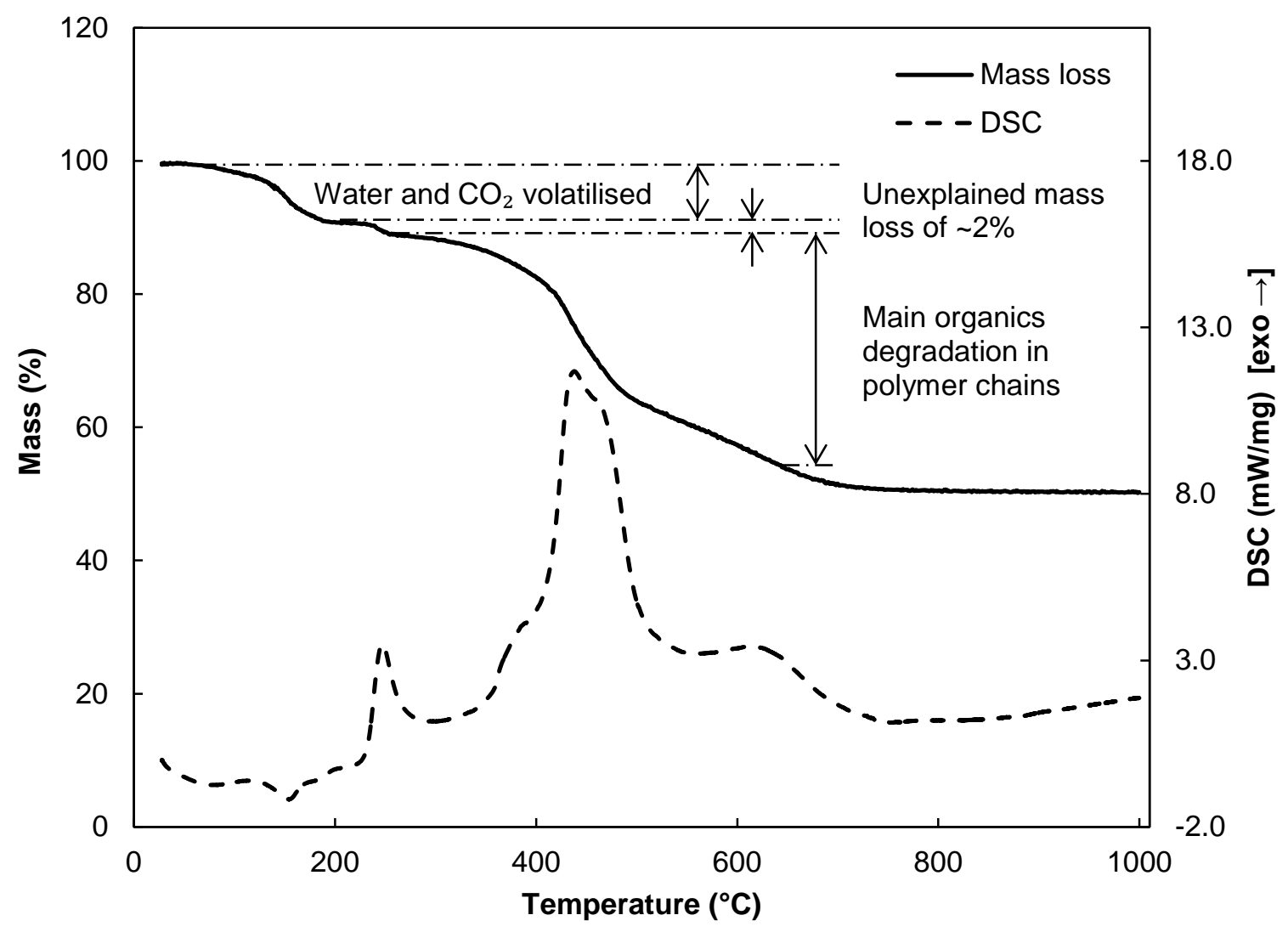

Fig. 5 Simultaneous TGA/DSC of APS film, cured at $105{ }^{\circ} \mathrm{C}$. Measurement was performed under air
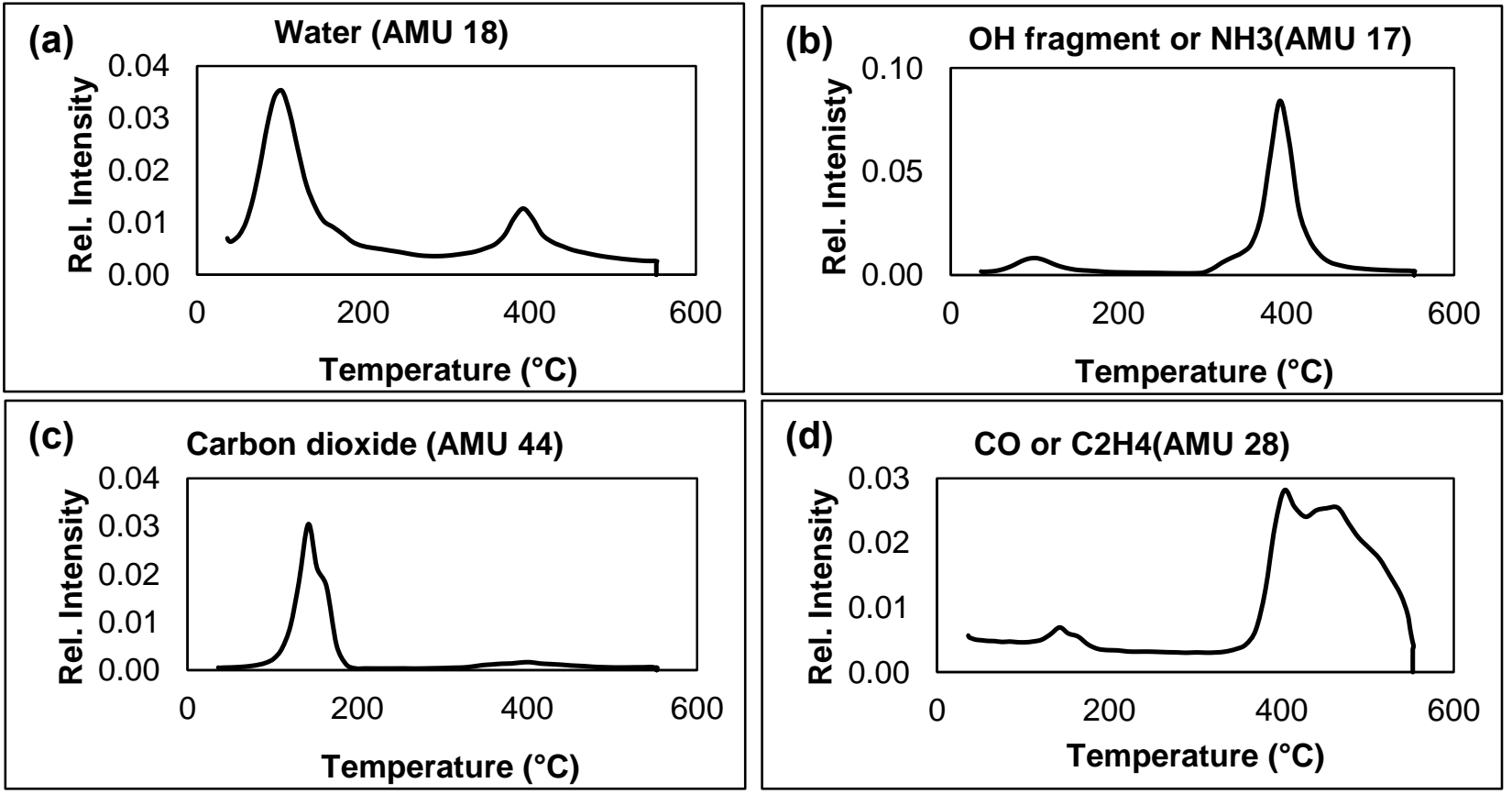

Fig. 6 CATLAB degradation profiles of (a) AMU 18 [water], (b) AMU 17 [OH- water fragment or $\left.\mathrm{NH}_{3}\right]$, (c) AMU $44\left[\mathrm{CO}_{2}\right]$ and (d) AMU 28 [CO or $\left.\mathrm{C}_{2} \mathrm{H}_{4}\right]$. Measurements carried out under helium atmosphere 